\title{
Liberdade e república na retórica do "pré-humanismo" italiano: um estudo sobre as obras do notário Albertano de Brescia (II95- I25I) e do dominicano Remígio dei Girolami (I247-I3I9)
}

Liberty and republic in the rethoric of the italian "pre-humanism": a study on the works of the notary Albertano da Brescia (II95-I25I) and the dominican friar Remigio dei

Girolami (I247-I3I9)

\section{Felipe Augusto Ribeiro*}

Resumo: O artigo versa sobre os conteúdos da retórica praticada pelos italianos entre os séculos XIII e XIV. O problema que investiga é a maneira como os italianos trataram, através dessa arte, as ideias de liberdade e de república. Partindo da tese de Quentin Skinner sobre a existência de um "pré-humanismo", o texto analisa os sermões e tratados produzidos pelos retóricos Albertano de Brescia (II95-I25I) e Remígio dei Girolami (I247I319), no intuito de verificar como os ideais supracitados aparecem em seus discursos. O objetivo do texto é tentar esclarecer os possíveis significados dessas ideias nas referidas obras, relacionando-as aos seus contextos de enunciação.

Palavras-chave: Retórica. República. Educação cívica.

Abstract: This paper deals with the contents of rhetoric as practiced by the Italians between the thirteenth and fourteenth centuries. It investigates how the Italians treated freedom and republic ideas by means of this art. Based on Quentin Skinner's thesis on the existence of a "pre-humanism", it analyzes the sermons and treatises produced by the rhetorical Albertan of Brescia (II95-I25I) and Remigio dei Girolami (I247-I319) in order to verify how the aforementioned ideals appear in their speeches. The aim of the paper is to

\footnotetext{
- Doutorando em História e Culturas Políticas na Universidade Federal de Minas Gerais (UFMG). Pesquisador do Laboratório de Estudos Medievais (LEME). E-mail: < felipeaur@gmail.com>.
} 
try to clarify the possible meanings of these ideas in those works, relating them to their contexts of enunciation.

Keywords: Rhetoric. Republic. Civic education.

\section{Introdução}

No âmbito dos estudos sobre o Renascimento, o historiador Quentin Skinner estabeleceu, em The foundations of the modern political thought ${ }^{\mathrm{I}}$, de 1978 , uma divergência fundamental em relação à geração que lhe antecedeu, ilustrada, sobretudo, por Hans Baron (I900-1988). Interessado na história das mentalidades e dos pensamentos, Skinner privilegiou, ao contrário de Baron, a continuidade histórica e lançou luz sobre as "origens" da Renascença, fazendo-a recuar cerca de dois séculos e iniciar não no Quattrocento, mas ainda no século XIII.

Skinner consolidou assim a tese da existência de um "pré-humanismo"2. O objeto sobre o qual ele alicerça sua tese é a retórica italiana. Para o autor, foram os retóricos das “cidades-repúblicas" do centro-norte da Itália, através do emprego da arte do falar e do escrever, que precipitaram o Humanismo ao estabelecer as bases para as noções de liberdade e de republicanismo que o Renascimento viria a consolidar. Segundo Skinner, esses dois termos não são apenas objetos de estudo privilegiados, são os ideais políticos fundamentais da Modernidade, como o título de sua obra seminal sugere.

Este artigo serve-se da proposta de Skinner como inspiração. Tomando o mesmo objeto de estudo pretende-se analisar como as ideias de liberdade e de república aparecem no discurso dos retóricos italianos dos séculos XIII e XIV, quais os limites de sua compreensão e seus possíveis significados. Para tanto, debruçar-se-á sobre dois mestres de retórica do período: o notário Albertano de Brescia (II95-I25I) e o frade dominicano Remígio dei Girolami (I247-I319), cujos trabalhos - tratados e sermões - não são abordados por Skinner.

Albertano de Brescia serviu à corte de diversos governantes e à administração pública de diversas cidades e Remígio dei Girolami lecionou e pregou em Florença. Ambos

I Com tradução realizada por Renato Janine Ribeiro e Laura Teixeira Motta em I996: As fundações do pensamento político moderno. Nas citações utilizaremos a versão inglesa, em uma edição de 2002, e recorreremos à versão brasileira para as traduções.

2 Este é o conceito empregado pelo autor para identificar os séculos XIII-XIV. Importa esclarecer que, se Humanismo e Renascimento não são sinônimos, Skinner parece tratar o primeiro como a dimensão mental ou intelectual, do segundo, este entendido como um período, um recorte do tempo histórico. 
pertenciam a famílias de estirpe popular, não nobres, e trataram das questões relativas à justiça, ao bem comum e à paz, afeitas às noções da liberdade e da república. Suas obras darão ao artigo um recorte temporal que vai de I238, data da primeira obra de Albertano, a I319, quando Remígio morreu.

\section{O problema do conceito de liberdade}

A tese de Skinner sobre o "pré-humanismo" se assenta em dois elementos principais. Primeiramente, o autor propõe que, em vista da dialética que as cidadesrepúblicas travaram, simultaneamente, com o Império e o Papado (e também que estes dois travaram entre si) é que os retóricos italianos, a serviço de suas comunidades, teriam desenvolvido uma ideia concisa, própria, de liberdade. No conceito deles, a liberdade era, primordialmente, o direito de se autogovernar e de não sofrer em sua política interna nenhuma interferência externa (SKINNER, 2002, p. 6; II); em outras palavras, para eles a liberdade seria sinônima de autonomia, de independência política (SKINNER, 2002, p. 7-8). Em segundo lugar, sugere-se que tal noção de liberdade estaria intimamente ligada à de república, que teria sido tomada como a forma de governo mais apta tanto para a defesa da liberdade quanto para o engrandecimento da cidade 3 .

No que tange à ideia de liberdade (tomada como autonomia), é patente a sua importância para vários retóricos do século XIII, como bem o mostra Skinner. Porém, esse conceito não parece ter a mesma acepção na obra de Albertano de Brescia. No corpus tratadístico e sermonário desse autor a propaganda da liberdade como valor de resistência às ingerências de imperadores e papas não aparece e para entender essa ausência parece ser necessário considerar o lugar sociopolítico que Albertano ocupou, bem como sua biografia. Como qualquer cidadão empenhado em seus deveres cívicos, Albertano também foi indicado pela sua cidade, Brescia, para representá-la, em uma embaixada, na segunda Liga Lombarda - que resistiu às investidas do imperador Frederico II (I994-I250) sobre as cidades italianas ${ }^{4}$-, entre I226 e I23I, e, nessa condição, foi indicado pela Liga para comandar a defesa do castelo de Gavardo, próximo à sua cidade. Paolo Guerrini (1960) indica que Gavardo era um "feudo episcopal ocupado pela comuna de Brescia como ponto nevrálgico da defesa contra as invasões do exército imperial”, o que prova a reputação de que Albertano devia gozar na cidade, para receber incumbência de tal envergadura. Ele

3 No Fundações (2002, passim) Skinner explora mais a ligação entre a república e a defesa da liberdade, e no Machiavelli’s (1990, p. I3I-I32) a relação a república e a grandeza cívica.

4 Para uma explicação do embate entre Frederico II e a Liga Lombarda, ver ARTIFONI, 2005. 
não teve êxito, porém, em sua função: o castelo teve que se render ao assédio inimigo, Albertano foi capturado e aprisionado em Cremona, sede das tropas imperiais (STOCCHI, 1970).

Esses primeiros eventos da carreira política de Albertano marcaram profundamente o seu primeiro texto, o tratado De amore et dilectione $D e i^{5}$, que ele dedicou, como faria com todo o restante de sua obra vindoura, a seus filhos (esse tratado foi endereçado especificamente ao filho Venâncio). A guerra e a prisão deveriam fazer Albertano enaltecer o valor da liberdade e opô-lo à opressão do Império, no entanto, não é o que se percebe. Mesmo em cativeiro, vítima dos imperialistas, o que preocupou Albertano nessa obra foi o afeto que ele achava que o homem devia sentir por Deus e pelos seus semelhantes (livros I e II da obra, respectivamente), bem como pelas outras coisas do mundo, "corpóreas" (livro III) e "incorpóreas" (livro IV). E logo no prólogo dessa primeira obra o bresciano explicita a sua intenção, por meio de citações bíblicas: "porque, como disse Jesus, filho de Sirá, 'antes de julgar, procura ser justo, antes de falar, aprenda'. E Salomão disse: 'o que responde antes de ouvir comete estultícia que é para vergonha sua"”6 . O que Albertano pretendeu, portanto, foi ensinar a seu filho a justiça e a arte da oratória.

No De amore Albertano assentou a sua base ideológica: apresentou a caridade (caritas, conceito recorrente em seu pensamento) - amor a Deus e ao próximo - e a justiça como os fundamentos da política, na medida em que produzem e regulam os dois vínculos necessários à vida coletiva, um com a divindade e outro com a comunidade. O que sobressai nesse argumento não é tanto a dimensão do afeto e da amizade ${ }^{7}$, mas a maneira como ela determinou a concepção que esse autor fez da liberdade de maneira distinta daquela que proposta por Skinner. A primeira diferença é que Albertano tomou a liberdade como fruto da graça divina, uma vez que, para ele, o amor a Deus ensina a virtude e esta é o fundamento do bom juízo, o qual implica em agir corretamente, segundo a "doutrina" (doctrina, conceito também importante no De amore) divina. Por todo o texto encontram-se citações que discorrem sobre Deus liberando e protegendo homens: o primeiro livro da obra se divide em capítulos, cada um versando sobre um motivo para o afeto que o homem deve dirigir a Deus, e o capítulo quinto, sobre a esperança, é todo

\footnotetext{
Os títulos de todas as fontes primárias que citaremos aqui foram dados a posteriori, por editores modernos. "Nam ut ait Ihesus filius Sirac, 'Ante iuditium para iustitiam, et antequam loquaris disce. Et Salomon dixit, 'Qui prius loquitur quam discat, ad contemptum et irrisionem properat'. Doctrinam ergo primo audias, deinde animo discas, postea vero mente retineas; animo enim vivimus, animo adiscimus, mente vero retinemus." (ALBERTANO DE BRESCIA, I980). Anota o editor da obra que a citação de Jesus foi tirada do Eclesiásticos, I8:19 e a de Salomão dos Provérbios, I8:13.

7 Para uma análise particular da importância da amizade na política citadina desse período, ver ARTIFONI, 2006.
} 
composto por essas narrativas. Não se pode esquecer, aqui, o peso de uma autoridade que não vinha da antiguidade romana, muito menos grega, e que foi onipresente na formação moral e intelectual desses homens: Agostinho de Hipona (354-430), citado por Albertano. No pensamento agostiniano, o dilema do livre-arbítrio - se o homem pode ou não fugir à doutrina divina - se resolve de maneira aguda: a liberdade de ação humana não está em fazer o que se quer, mas em fazer o certo; a questão é de escolha e para fazê-la é necessário um discernimento que só se obtém na observância da doutrina, pois ela ensina a verdade e a justiça.

O tema tem, portanto, tudo a ver com a dimensão da justiça. Daí a recorrência, cremos, da análise da atividade deliberativa - a qual, para Albertano, devia ser feita na observância religiosa - típica do ofício judiciário. Assim como o tema da observância religiosa, tal análise marcará presença nos textos posteriores de Albertano. Sua formação na universidade de Bolonha (GUERRINI, 1960) levou-o, findado o seu cativeiro, a assumir magistraturas judiciárias ${ }^{8}$ em diversas cidades do centro-norte italiano e a acompanhar as comitivas de homens eleitos, aqui e acolá, para exercer o potentado ${ }^{9}$ da cidade $^{\text {Io }}$. De fato, Albertano foi registrado na corporação dos juízes de Brescia (GUERRINI, 1960). E foi durante esse período de sua carreira que ele escreveu suas demais obras: em I245 escreveu um tratado exclusivo sobre a arte da retórica, o Ars loquendi et tacendi (dedicado a seu filho Estéfano), no qual ele explana não apenas sobre o bem falar, mas também sobre os momentos, condições e utilidades do silêncio - ou, mais precisamente, sobre os limites da retórica, estabelecendo as condições sem as quais o aconselhamento não poderia ser exercido $^{\text {II }}$. No ano seguinte deu à luz o Liber consolationis et consilii, endereçado ao seu filho João, um médico (ou seja, alguém que, como o pai, também cumpria o papel de aconselhar as pessoas, e Albertano aproveita essa comunhão para empregar as inúmeras analogias, correntes na época, entre a medicina e a política) que visa a instruir o leitor especificamente na arte da consolação diante de tragédias e do aconselhamento com vistas à tomada de decisões. Ou seja, o autor deu continuidade à proposta formulada em sua

8 Albertano foi notário (notarius) e esta função frequentemente se acumulava com a de juiz (iudex) ou era, até mesmo, sinônimo dela, entendido aqui não como um árbitro, alguém que julga, mas como um assessor do verdadeiro árbitro, o potentado, e responsável por aconselhá-lo e por despachar as suas sentenças.

9 Esmiuçar os regimes comunais italianos, em suas diversas fases, instituições, dinâmicas e estruturas excederia o espaço que temos aqui, portanto nos limitamos a referir algumas leituras capazes de esclarecer bem esse panorama: ARTIFONI, I990, 2003 e 2005; GILLI, 20II. Como dissemos, o próprio Skinner (2002, p. 3-I2) perpassa esse panorama, oferecendo algumas informações iniciais para o entendimento desse contexto.

Io Para uma análise da itinerância dos potentados e das suas comitivas, que faziam circular ideias e técnicas de governo, contribuindo para certa padronização dos regimes comunais por toda a Itália centrosetentrional, ver ARTIFONI, 2 oIo.

II Enrico Artifoni abordou especialmente esse tratado de Albertano em 2004 e 2010. 
primeira obra de ensinar seus leitores a falar e, ao mesmo tempo, a serem justos, aptos a exercerem a justiça.

No Ars loquendi o tema da liberdade sequer tem aparição considerável; há apenas uma ocorrência de um correlato do termo libertas, o verbo liberare, e ele faz parte de uma citação de Gregório Magno (540-604) que alude à célebre passagem onde Cristo livra uma adúltera que era humilhada pelos judeus e inquire os agressores sobre os seus próprios pecados $^{\mathrm{I2}}$; a citação encontra-se num trecho em que Albertano argumenta que ninguém pode culpar outrem se não leva uma vida absolutamente inocente, livre de culpas e pecados, ou seja, que não se pode ser juiz sem levar uma vida virtuosa. Novamente, portanto, uma relação entre liberdade e moral individual, ancorada da doutrina religiosa e valendo-se de referências escriturárias e canônicas. Noção que se distancia, portanto, da ideia de liberdade enquanto autonomia citadina.

Já no Liber consolationis o conceito de libertas e seus correlatos aparecem com mais frequência. Talvez essa seja a obra mais inovadora de Albertano, onde ele cria personagens (Malibeu e Prudência), entre outros, e constrói diálogos que estabelecem uma verdadeira contenda ideológica sobre um amplo espectro de elementos da deliberação colegiada, do exercício judiciário, da tomada de decisões e da elaboração e execução de sentenças. Logo, mesmo nesse inusitado texto a liberdade está intrinsecamente ligada à justiça. No capítulo $\mathrm{V}$, por exemplo, propõe-se que através de conselhos prudentes, que promovam a justiça, cidades podem ser liberadas da violência ${ }^{\mathrm{I3}}$. É curioso observar aqui que quem dá os conselhos corretos a Melibeu, o protagonista da história, é a própria Prudência, que se apresenta como sua esposa. O enredo da história conta que, na ausência de Melibeu, seus vizinhos invadiram sua casa e violentaram a sua esposa. Melibeu, por isso, desejava vingança e, para tanto, contava com o apoio, expresso através de conselhos incautos oferecidos por falsos amigos (em verdade, rivais invejosos) reunidos em assembleia e que, longe de zelarem pela sua dignidade, queriam vê-lo arruinar-se em brigas infindáveis. Sua

I2 "Qui alium arguit depeccatis, a peccatis debet esse alienus, exemplo Christi, qui mulieremin adulterio deprehensam absolvit, et liberavit a pessimis Judois, quiaccusabant et judicabant peccatricem, quum ipsimet scelerosissimi forent" (ALBERTANO D BRESCIA, I873).

I3 "Similiter et Judith per bonum suum consilium liberavit civitatem, in qua morabatur, de manibus Holofernis, qui illam obsidendo destruere volebat. Similiter et Abigail per suum bonum consilium virum suum Nabal ab ira David regis liberavit, qui eum interficere volebat" (Ibid.). Repare-se que as conselheiras, nesse capítulo, são mulheres; de fato, essa parte do texto versa sobre a capacidade conselheira das mulheres. Pesa nessa definição de gênero o fato de que a Prudência, presidente da deliberação e das boas decisões - da justiça, por conseguinte - tenha uma representação histórica feminina, que remonta, talvez, a uma alegoria grega presente na peça Oréstia, de Ésquilo, onde Atena, deusa da justiça, funda o primeiro tribunal ateniense na ocasião de apaziguamento de uma guerra que estava prestes a estourar. Atena conta com a ajuda de mais duas divindades femininas, Peitó (a beleza) e Cáris (a graça, ou seja, a persuasão), e consegue restituir os danos que cada parte havia sofrido nas agressões que trocaram, convencendo-as de que o conflito aberto seria destrutivo para ambas. As atuações de Atena em Ésquilo e da Prudência em Albertano são muito parecidas. Para uma análise dessa alegoria grega, ver MEIER, I997. 
esposa, embora vítima principal da agressão, é que emerge, então, para criticar os vícios dos conselheiros, impugnar a assembleia e ponderar a decisão do marido ${ }^{\mathrm{I}}$. Não foi à toa, pois, que Albertano lhe dera o nome de Prudência: a sugestão era a de que essa virtude deveria presidir qualquer deliberação, mesmo as mais graves.

Sempre que se estudam os tratados deve-se perguntar sobre o alcance de suas circulações; se eles foram realmente lidos, individualmente ou em público, ou não; para quem foram endereçados; informações como essas limitam as análises que se podem fazer desses textos. Segundo um biógrafo do autor, Angelo Monteverdi (1929), os tratados de Albertano tiveram larga difusão e foram frequentemente copiados e citados; o próprio Bruneto Latini (I220-I294), outro retórico italiano, bem conhecido de Skinner, teria transcrito partes inteiras de Albertano em sua (MONTEVERDI, I929; STOCCHI, 1970). A circulação através de cópias, contudo, demanda tempo. Cabe, então, neste ponto, lembrar outra parte do corpus "albertanita" que pode ter encontrado impactos mais imediatos, nos meios em que o próprio autor circulava: seus sermões. Sabe-se que esse gênero retórico podia ser primeiro escrito e depois oralizado ou vice-versa, quando um amanuense (ou o próprio autor) se encarregava de registrá-lo por escrito, às vezes no mesmo momento em que era proferido.

Desde que saíra da prisão Albertano vinha proferindo sermões, paralelamente à confecção de seus tratados (com os quais há muitos intercruzamentos) em diversos ambientes: o primeiro foi em I243, o Sermo ianuensis, pregado entre os causídicos (seus pares, porque o autor também exercera essa profissão) de Gênova. O bresciano fora convidado para proferir tal palestra porque pertencia à comitiva do senhor Emanuel Maggi, um conterrâneo seu que havia sido eleito pelos genoveses para exercer o potentado da cidade naquele ano (GUERRINI, I960). Como a epígrafe do texto informa, o sermão teve lugar na casa de um dos causídicos, senhor Pedro de Nigro, no dia de São Nicolau. Nesse sermão, porém, o tema da liberdade também não aparece, assim como nos seus outros quatro sermões, alguns proferidos entre frades franciscanos, com quem Albertano manteve íntima convivência e de cujo programa de pacificação participou (GUERRINI, 1960). Em suma, como já se havia constatado, o conceito de libertas citadina, em oposição ao Império e ao Papado, não nos parece chamar a atenção desse autor. No lugar dela, protagoniza o seu pensamento a justiça. E a razão para essa particularidade é contextual: em meados do século XIII, quando Albertano vive e escreve, as cidades já haviam vencido o Império uma vez, na época de Frederico I, o Barbarruiva (II22-II9o), e começavam a explicar seus

I4 Para um estudo específico do Liber consolationis, cf. ARTIFONI, 2004. 
problemas a partir de suas lutas internas, não externas. Albertano presenciou uma época ameaçada pelas vendette ${ }^{15}$ - por isso elas compõem o enredo do Liber consolationis (ARTIFONI, 2004, p. 196-197) - e pelas guerras civis que atormentavam cada cidaderepública.

Em função da detecção de um problema diferente é que a justiça ocupa o lugar central da obra, ao invés da liberdade. Albertano confiou que o bom exercício da justiça era a única maneira de pôr fim à lógica destrutiva, ao ciclo vicioso das vinganças, que engendravam violências e conflitos intermináveis. A solução dos problemas citadinos não era, portanto, segundo Albertano, lutar contra forças externas e garantir o autogoverno, mas educar a própria comunidade citadina acerca da justiça e da cidadania. Albertano pôsse a ensinar seu público não só sobre as virtudes que devem caracterizar o cidadão, como a prudência, mas também sobre os métodos e as técnicas de governo, como o falar, o aconselhar e mesmo o calar. O primeiro ensinamento ele dirigiu a seus filhos; poder-se-ia pensar que esse destinatário pessoal teria limitado o escopo de seus tratados, mas já se observou que eles tiveram bastante circulação para além de sua família, o que autoriza a pensar que, embora os interlocutores diretos dessas obras fossem os filhos, tal destinatário cumpriu ali uma função meramente formal, pois, em verdade, a obra se dirigiu a todo cidadão. Parece, pois, uma metonímia: tomar os filhos para falar de todo cidadão. O que se compreende, afinal, a tarefa primeira do pai é educar o filho e Albertano não esqueceu disso, pois no prólogo do livro I do De amore ele lembrou ao filho que a motivação para escrever-lhe nascia do profundo amor e dileção paternos que ele lhe dirigia ${ }^{16}$. Mas educar o filho aqui equivale a educar o cidadão.

No segundo livro desse tratado, versando sobre o amor entre os homens, Albertano indicou que, desde que ele seja universal, entre irmãos, esposos, ricos e pobres, velhos e jovens, é capaz de produzir a concórdia ${ }^{17}$. Ali mesmo ele estabeleceu uma conexão, lembrando São João, que torna o amor entre homens condição do amor a Deus: “como São João disse em sua carta: 'todo aquele que ama o irmão nasceu de Deus e conhece Deus.

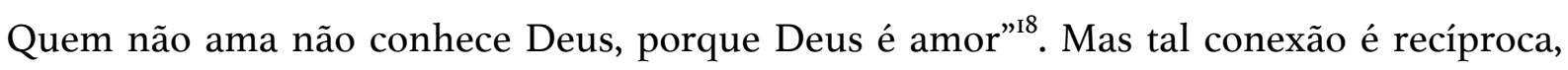
pois Albertano acrescenta, ainda com João: "Se alguém diz: eu amo a Deus, e odeia a seu

15 Estudo acurado sobre as vendette se encontra em ZORZI, 2002; 2008; 2009.

I6 "Quanto amore quantaque dilectione mea paterna caritas tuam diligat filialem subiectionem, vix tibi possem narrare, vel lingua mea posset aliquatenus explicari" (ALBERTANO DE BRESCIA, I980).

${ }_{17}$ "In tribus placitum est spiritui meo, que sunt probata coram Deo et hominibus: concordia fratrum, et amor proximorum, et vir et uxor sibi consencientes. Tres autem species odivit anima mea: pauperem superbum, divitem mendacem, et senem fatuum et insensatum" (Ibid.).

I8 "Ut sanctus Iohannes in epistola sua dixit, "Et omnis qui diligit fratrem, ex Deo natus est, et cognoscit Deum. Qui non diligit, non novit Deum: quoniam Deus caritas est” (Ibid.). Citação tirada de I João 4: 7-8. 
irmão, é mentiroso. Quem não ama seu irmão, que pode ser visto, como pode amar a Deus, que não pode ser visto? De maneira que temos o mandado de Deus: quem ama a Deus, ame também a seu irmão"19. Albertano ensinou aos cidadãos de seu tempo, portanto, o amor (caritas ou dilectio).

A vinculação entre amor e justiça fica clara em seus sermões. Não só os dois termos, caritas e iustitia, convivem estreitamente no léxico de suas falas, como há entre eles um nexo causal. O segundo sermão albertanita (Sermo II) inseriu num momento favorável a essa ligação, pois foi proferido durante uma reunião feita entre franciscanos e causídicos de sua cidade, Brescia, na qual os pediriam doações à administração pública. A oração de Albertano foi ao sentido de favorecer as doações, porque ele as entendia como um ato de amor ou caridade, componente da justiça que os magistrados deviam dispensar à comunidade citadina. O notário não entendia que aquela doação se limitava aos frades e lembrava que todos estavam ali reunidos também em prol dos pobres (pauperum) (ALBERTANO DE BRESCIA, 1997b), por quem deviam zelar. Repetindo uma fórmula presente em outro sermão (Sermo I), feito para os frades, em seu convento, Albertano propôs que aquela reunião servia à "iluminação" ou à "alimentação espiritual”, tão importante quanto a alimentação corporal ${ }^{20}$. Não eram importantes somente as doações, portanto, com as quais se esperava que os frades pudessem exercer sua função de atendimento aos desvalidos; era necessário que todos estimulassem a sensibilidade (intellectu) na direção da caritas e, para isso, o orador sugeriu à sua plateia que todos deviam pregar também "para os pobres e miseráveis, para os ricos e poderosos, para a justiça dos cônsules e para outras jurisdições existentes, assessorando-os, com zelo, em suas causas"”I . Tratava-se de exercer o ofício judiciário na iluminação, na observância do amor. Em Albertano, para que o juiz exerça bem o seu poder arbitral, julgando com prudência e compaixão, ele precisa amar. $\mathrm{O}$ amor e a justiça passavam tanto pelo cuidado material, materializado nas doações, quanto pela atividade da pregação e do assessoramento, pertinentes à profissão do causídico e do notário.

Se o conceito de liberdade, tal como o toma Skinner, não aparece na obra de Albertano, tampouco na de Remígio dei Girolami, frade dominicano que nasceu nas

I9 "Si quis dixerit quoniam diligo Deum, et fratrem suum odit, mendax est. Qui non diligit fratrem suum quem videt, Deum, quem non videt, quomodo potest diligere? Et hoc mandatum habemus a Deo: qui diligit Deum diligat et fratrem suum" (Ibid.). Referência a I João 4: 20-2I.

20 "Fratres mei, ad honorem Dei et refectionem pauperum, more solito congregati sumus. Ut ergo Deus honoretur propter nostram congregationem et refectio nostra plena sit, antequam accedamus ad corporalem refectionem, animas nostras reficiamus de cibis spiritualibus [...]" (Ibid.).

2I "Orare eciam debemus, pro egenis et pauperibus, presides et divites et consules iusticie et alios iurisdictionem habentes et in causis eorum libenter assister" (Ibid.). 
redondezas de Florença e ali pregou e lecionou, assim como em Paris, onde se formou e foi aluno de Tomás de Aquino (I225-I274). Remígio diferencia-se de Albertano tanto pela formação parisiense e escolástica quanto pelas profissões que desempenhou, pelo lugar social que ocupou e pelos espaços que frequentou. Enquanto o bresciano pregou em reuniões fechadas e para plateias pequenas, o florentino era homem de multidão: seus sermões foram pronunciados em praça pública, em dias litúrgicos que convocavam todos os citadinos à comunhão. O primeiro participou de uma etapa específica do governo citadino, a fase podestatal, caracterizada pelo governo executivo e arbitral desse grande senhor que era o potentado, cercado por uma cúria de notários, causídicos, juízes e uma série de outros funcionários públicos e magistrados. O segundo assistiu, do começo ao fim, à emergência, à radicalização e ao declínio da última fase desses governos republicanos: a popular, marcada por instituições e por técnicas de governo que ampliaram enormemente a participação política para as classes não-nobres (os popolani) e que, em Florença, chegou a ostracizar parte da aristocracia e a promulgar leis que lhes retiravam direitos políticos antiquíssimos ${ }^{22}$.

Assim como para o notário, os percursos e posições de Remígio determinaram profundamente sua obra. Seus principais textos são três tratados e um conjunto de sermões, dentre os quais temos alguns publicados por Emilio Panella e vários outros perdidos ou inéditos. O primeiro tratado é o De bono communi, de $\mathrm{I}_{30 \mathrm{I}^{23}}$, que versa sobre o bem comum como ideal de governo, responsável pela paz e pelo bem-estar social; o segundo é o De bono pacis (1302), que fecha a relação entre bem comum e paz reafirmando o segundo como produto do primeiro, ou, dito de outra maneira, aquele como condição. De sua coleção de sermões será abordado aqui apenas o conjunto reunido e intitulado por Emilio Panella ${ }^{24}$, editor do corpus remigiano, como Sermones de pace - compostos entre I3I4 e I3I6 - porque ali se encontram textos em comum a lida com o problema da paz cívica, muito afeito aos ideais de justiça, liberdade e república.

Conquanto tenha biografia um pouco díspare e tenha ocupados lugares e tempos distintos, Remígio e sua obra convergem com o pensamento de Albertano de Brescia no que tange à ideia de liberdade. Das obras remigianas a única que faz alguma menção

22 Para as informações biográficas acima mencionadas, cf. Sonia Gentili (200I), em artigo que biografa o frade e resume o exaustivo trabalho de Emilio Panella. Antes de Panella, há também outra biografia sobre Remígio, de autoria de Ovidio Capitani (1970).

23 As datações das obras de Remígio são ainda menos seguras que as de Albertano.

24 Quase tudo o que sabemos sobre Remígio se deve ao trabalho de Panella, que também é frade dominicano e reside no mesmo convento onde o próprio Remígio viveu, Santa Maria Novella. Panella devassa, desde I979 - quando defendeu, na universidade de Florença, tese acerca do tema - os arquivos sobre o antigo frade e editou quase toda a sua obra, além de produzir inúmeros artigos sobre ele. 
significativa, ainda que escassa, ao léxico da liberdade é o De bono comuni, no qual o autor tenta provar que, de toda maneira, o bem comum deve ser anteposto ao bem privado. Ali, tal como no discurso albertanita, a liberdade também não é um problema de autogoverno citadino, mas de educação individual, subjetiva, tanto cívica quanto religiosa. Remígio, como Albertano, também lança mão, em seu nono capítulo, das autoridades de Santo Agostinho (no De libero arbítrio) e de Aristóteles (na Ética a Nicômaco) para afirmar que é no quadro do livre-arbítrio que nasce o amor que zela pelo bem comum, porque vincula cada homem aos seus semelhantes, faz com que cada cidadão se preocupe com seu compatriota. Similarmente, apresentam-se, no capítulo I2, as virtudes - inclusive as da prudência, da justiça e da misericórdia - como bases do bem comum.

Em suma, Remígio, assim como Albertano, coloca o amor e a virtude como remédios para os problemas que identificam. Eles não parecem ter se preocupado com as guerras externas que suas cidades travaram, mas com os dissensos que as corroíam por dentro, com as vinganças e com os conflitos entre os partidos populares e os aristocratas. Embora as estratégias que cada um escolheu para atacar o problema proposto tenham pequenas diferenças entre si - Albertano, jurista, escolhe instruir seus pares no sentido do bom funcionamento da justiça, inclusive em seu exercício oratório; Remígio, por sua vez, preferiu educar as multidões para a observância da caritas - ambos apostaram na educação individual, cívica, como mecanismo de manutenção da justiça e, por conseguinte, de preservação da paz. Ou seja, em ambos, o bom funcionamento da justiça e a experiência do amor fraterno é que edificavam e mantinham a paz.

Cabe, contudo, explicitar melhor a relação que a educação - e seus conteúdos: amor, paz e justiça - guardam com a ideia de liberdade. Nesse sentido, uma curta passagem de Remígio é esclarecedora. Em seu capítulo oitavo, evocando, através da Legenda Aurea de Iacopo de Varazze (I230-I298) - o bispo inglês Tomás de Canterbury (III8-II70), Remígio defende o ideal da libertas ecclesiae, isto é, da autonomia da Igreja em relação ao Império. Nesse trecho sim se encontra o significado de autogoverno e de resistência a ingerências externas. Todavia, o que parece interessar a Remígio é a maneira como Tomás, na representação que Iacopo faz dele, defendeu essa liberdade: com a própria virtude, vivendo na mais plena observância religiosa. A ideia contida nesse excerto, portanto, é a de que o homem virtuoso, justamente como o vislumbram Albertano e Remígio, é o mais apto a lutar pela defesa de sua comunidade, não apenas no sentido do combate às suas querelas internas, mas também no sentido de protegê-la contra inimigos externos. Há, portanto, uma conexão entre uma noção de liberdade que é individual, vivida no amor e na justiça e é esse o cerne da questão, para Albertano e para Remígio - e outra que é cívica, referente 
à defesa da própria comunidade. A diferença em relação às conclusões que Skinner elabora a partir de outros retóricos é que o notário e o frade não apostam num tipo específico de regime nem na força de instituições governativas para promover a liberdade, mas sim na educação dos cidadãos.

\section{Os significados do republicanismo}

Para Quentin Skinner a "redescoberta” de Aristóteles pelo Ocidente é que permitiu aos italianos avançar em sua ideologia política. Além de importar os comentários de Tomás de Aquino (I225-I274) sobre a obra aristotélica, os retóricos se valeram também das bases éticas que até aquele momento haviam sido desenvolvidas mediante a leitura de Cícero. Sobre essa dupla autoridade eles puderam pensar na forma de governo que melhor garantiria a liberdade. E eles teriam chegado a uma conclusão: a melhor forma de governo seria a república.

Ora, tendo Remígio estudado com Tomás de Aquino em Paris e conhecido Aristóteles - de fato, o frade é reputado como o maior disseminador do pensamento aristotélico na Florença de seu tempo (CAPITANI, 1970) - era de se esperar, com Skinner, que ele fizesse essa ligação entre liberdade citadina e forma de governo. Já se viu, entretanto, que esse tipo de liberdade, tal como em Albertano, não lhe preocupa. Cabe agora verificar se no pensamento de Remígio podem-se identificar alusões à república como a melhor forma de governo, já que Albertano de Brescia não tem nada a dizer a esse respeito.

A despeito de sua distância cronológica e dos distintos regimes de governo sob os quais viveram, Remígio e Albertano passaram por períodos extremamente conturbados, politicamente efervescentes, de muitos conflitos e violências. Ambos fizeram parte do popolo, cada um em sua cidade natal, e sentiram na pele as mudanças sociais que os perpassavam: se Albertano compôs embaixadas e tomou partido em uma batalha, Remígio (impedido pelo seu voto eclesiástico de ocupar magistraturas e de empunhar armas), ao retornar de Paris, representou o seu convento, Santa Maria Novella, em diversos momentos e âmbitos e, tal como o notário, nesse ofício circulou por várias outras cidades da região, estabelecendo contatos com autoridades eclesiásticas em diversos níveis. A seu modo, o frade também se envolveu com a política de sua cidade: enquanto Albertano, amigo dos franciscanos, mediava suas petições junto à magistratura citadina, Remígio, ele próprio frade, é quem fazia esse tipo de requisição em nome de seu estabelecimento. Era ele, à semelhança dos frades que ouviam os sermões de Albertano, um dos encarregados da 
atividade pastoral e caritativa de seu convento. Ademais, Remígio também desempenhou, indicado pelo seus superiores, funções arbitrárias e mediadoras em disputas territoriais travadas por outros estabelecimentos eclesiásticos (GENTILI, 200I).

Nos sermões proferidos entre I3I4 e I3I6 e posteriormente registrados por escrito por um amanuense (sob a coordenação do próprio frade) Remígio retomou muitos dos argumentos elaborados em seus tratados anteriores. No De bono comuni o tema da república está presente, contudo, ela também não tem, nesta obra, a acepção que se esperava. $\mathrm{O}$ texto, construído segundo o método escolástico, divide-se em capítulos, cada um dedicado a provar, por meio de um argumento particular, a proposta anunciada no prólogo. $\mathrm{O}$ capítulo dois é o mais revelador para o que estamos investigando. $\mathrm{O}$ anúncio do tratado é a tese de que "o bem comum é mais desejável que o próprio bem privado" (Quod bonum comune preferendum sit bono privato proprio) e nesse capítulo o frade tenta prová-la mediante a "autoridade dos pagãos" (auctoritate infidelium) (REMÍGIO DEI GIROLAMI, I985a). A tese apresentada é antiga e oriunda justamente de Aristóteles, mas a autoridade primordial a que se recorre para prová-la ainda é Cícero (que, por sua vez, dialoga com Platão); do De oficiis Remígio tira palavras do antigo romano:

\footnotetext{
"aqueles que se dedicam à república, observem dois preceitos de Platão: primeiro, que se preserve o interesse dos cidadãos, informando-lhes as ações do governo, livres de interesses pessoais; depois, que se cuide do corpo da república em sua totalidade, para que, satisfazendo-se uma parte, não se negligenciem as outras" ${ }^{25}$.
}

Nesse trecho bem comum e república parecem bastante próximos. Mas o mais importante nele é notar que se fala em "corpo da república” (corpus rei publice). Fala-se também na totalidade dos cidadãos, o que nos leva a crer que aqui república tenha o sentido de corpo cívico, não de forma de governo. É um sentido muito afeito ao de civitas, outro termo comum no discurso ciceroniano e replicado por seus intérpretes e comentadores, inclusive Remígio. De fato, em algumas passagens Emilio Panella traduz res publica por "comunidade política", sentido comumente atribuído à ideia de civitas. Para evitar uma possível confusão entre os dois conceitos, propomos um esclarecimento: lembrando que res publica é uma locução, podemos imaginar república como uma maneira de compreender a comunidade política; a coisa (res) é a própria comunidade e pública é a

25 "Item in libro I De officiis: 'Qui rem publicam professi sunt, duo precepta Platonis teneant: unum quod utilitatem civium sic tueantur ut, quicquid agant, ad eam referant, obliti commodorum suorum; alterum ut totum corpus rei publice curent ne, dum aliquam partem tuentur, reliquas deserant"' (REMÍGIO DEI GIROLAMI, I985a). 
maneira como ela deve ser tomada e respeitada pelos governantes. Esse caráter de publicidade da coisa pública é que Remígio está apontando, com Cícero, inclusive asseverando que os governantes devem ser transparentes e informarem os cidadãos das decisões que tomam.

Mesmo em Cícero, república não parece ter o sentido de uma forma, de uma organização institucional e prática do governo, da política. República parece um modo de entender a comunidade. O que interessa é que o governo deve ser público, no sentido que Remígio demonstra ter em conta: colocar o bem comum em primeiro lugar e satisfazer todos os cidadãos de forma equânime. A civitas é, afinal de contas, a comunhão de todos os cidadãos; logo, ela pertence a todos eles, e por isso os governantes devem considerá-la "coisa pública". Em alguns trechos Panella traduz res publica por Estado, que é a palavra moderna para a coisa pública, ou seja, a república. O Estado (status), estático, permanece enquanto os cidadãos passam, por isso o bem comum deve prevalecer sobre os particulares; a comunidade política é perene.

O excerto acima (e muitos outros) é replicado no De bono pacis, ou seja, neste texto a compreensão de república é a mesma. Nele, a questão é refletir se

para o bem da paz e da concórdia entre cidades, castelos e outras comunidades, pode-se condenar, por injúrias e danos sofridos e causados, na concordância das respectivas comunidades e por meio de compensação recíproca, sem o consenso de cada pessoa física daquela cidade ou daquela comunidade, ou mesmo contra a vontade delas, vítimas das injúrias e dos danos, incluídos os clérigos ${ }^{26}$.

Como se viu, o horizonte de Remígio, tal como o de Albertano, também é conflituoso. A questão que ele trava também diz respeito à justiça: trata-se de decidir se as reparações diante de prejuízos físicos e patrimoniais devem ser imputadas pelo público, ou seja, pelo governo, ou se as pessoas particulares envolvidas da violência podem buscá-las por conta própria - isto é, praticar a vendetta, costume antigo que algumas cidades tentaram regulamentar, outras tentaram proibir e punir. A resposta de Remígio é afirmativa: sim, a justiça pública deveria se impor e se encarregar das devidas restituições

26 "Pro bono pacis et concordie inter civitates et castra et alias comunitates possit fieri remissio iniuriarum et dampnorum illatorum et receptorum per ipsas comunitates ad invicem componentes sine assensu omnium personarum particularium illius civitatis seu comunitatis, immo contra voluntatem aliquarum personarum passarum iniurias et dampna, etiam ecclesiasticarum" (REMÍGIO DEI GIROLAMI, I985b). 
diante da violência. E, novamente, ele tenta provar a sua tese à moda escolástica, recorrendo a múltiplas autoridades.

Nos sermões o tema da república não aparece. Mas, assim como nos textos anteriores, está presente uma noção mais ampla de coisa pública. No sétimo sermão, por exemplo, que trata da ilusão de segurança que as armas fornecem, Remígio defendeu que a cidade garanta, em seus estatutos, assistência aos "religiosos pobres e a outros necessitados" (religiosis pauperibus et aliis indigentibus) (REMÍGIO DEI GIROLAMI, I985C), porque a única maneira de garantir a segurança e a paz da comunidade é, como se desenvolveu no De bono communi, satisfazendo a todos os cidadãos e viabilizando o exercício da cura animarum, responsável por educá-los.

Emerge nesse ponto, então, outra semelhança em relação à proposta de Albertano de Brescia: em seu oitavo sermão Remígio afirma que a paz é feita "pelo governante sábio" (facit pacem discretus rector ad modum sapientis), pela "observância dos governados" (obedientia subditorum), pelo "amor" (dilectio) e pelas "provas do amor" (probatio dilectionis per opera) (REMÍGIO DEI GIROLAMI, I985b). Ambos concebem a política como uma atividade regida pela moral, isto é, pelas qualidades pessoais, subjetivas, dos indivíduos. Professores - um de magistrados, outro de frades, mas ambos com ocasiões de dirigir-se ao cidadão comum -, puseram-se, então, a educar seus concidadãos no sentido da moral, dirigindo suas plateias à observância religiosa, e da ética, isto é, das normas que deviam ditar a participação política (em assembleias e conselhos, como no Liber de consolationis) e o exercício do governo, afinal, os dois assistiram a uma crescente ampliação das vias de acesso do povo ao poder. Albertano, como se verificou, pontuou a necessidade de exercer a justiça na observância da doutrina. Remígio, por sua vez, foi enfático com o seu ouvinte/leitor: "a paz é feita na tua virtude" ${ }^{27}$, que podemos entender como: a paz começa dentro de ti.

Conforme os regimes podestatais se desenvolveram e, sobretudo, com a invenção dos regimes populares, a possibilidade de ocupar magistraturas como a de juiz e a de conselheiro se abriu para muitos homens que, privados da mesma educação a que as elites tinham acesso, precisariam aprender, de algum modo, os princípios do bem comum e da paz, imprescindíveis ao bom exercício do poder. Ambos entenderam a justiça como um mecanismo privilegiado de administração da comunidade (ou do Estado) e a relacionaram ao atendimento das necessidades de todos os cidadãos, inclusive os pobres (considere-se que o frade era mendicante e o notário, mesmo laico, partilhava da ideologia franciscana).

${ }^{27}$ "Fiat pax in virtute tua" (Ibid.). Referência a Salmos I2I: 7. 
Ou seja, relacionaram-na à preservação do bem comum, condição de manutenção da paz. Era o que todo potencial governante precisava saber e seguir.

Já em seu livro de 1978 Skinner apontou que alguns retóricos italianos preferiram a saída da moralização da política como resposta para os problemas que enfrentavam. Já em um artigo de 1990 (p. I4I-I42) ele atualizou a sua tese incluindo nela uma análise dos ideais de justiça e bem comum. Ali o autor explicitou a conexão entre justiça, bem comum e paz, em que a primeira garantia, na visão dos autores estudados, a segunda, e esta garantia a terceira. O que se verifica é que Albertano e Remígio representam justamente dois autores que fizeram essa opção, de explicar os problemas que identificavam por meio da moralização e da educação cívica e não da proposição de formas e instituições que fossem mais apropriadas ao governo citadino. Uma opção que parece se voltar mais para as dinâmicas dos poderes locais, intracitadinos, não de poderes universais. Para retóricos como Albertano e Remígio, eram as lutas internas de cada cidade, não os seus embates com os imperadores e papas, o grande problema, o motivo de ruína de muitas cidades e, por conseguinte, o objeto sobre o qual refletir. Diante disso, a forma do governo (especialmente no que tange aos seus contornos institucionais) não importava, por isso Albertano e Remígio não desenvolveram nada a respeito de repúblicas, monarquias, oligarquias ou mesmo tiranias.

As dissonâncias que Albertano de Brescia e Remígio dei Girolami representam no universo dos retóricos italianos, considerando, inclusive, aqueles abordados por Skinner, nos obriga a relativizar a avaliação que fazemos dessa temporalidade. Eles denunciam que tais profissionais (os dictatores) não podem ser tomados de forma homogênea durante o período o que vai de fins do século XI até o século XIV. Nesse sentido, é útil uma tese defendida por Enrico Artifoni: para esse autor os dictatores devem ser consideramos, pelo menos, como componentes de três gerações distintas. A primeira delas se situa entre os séculos XII e XIII e tem como expoente mais ilustre o mestre Boncompagno de Signa (c.II65-I240), bastante explorado tanto por Skinner quanto pelo próprio Artifoni ${ }^{28}$. A segunda ocupa a faixa central do século XIII e é representada por Albertano de Brescia, dentre outros. A terceira, por fim, se encontra na passagem para o século XIV e tem Remígio como um de seus membros.

Entre cada uma dessas gerações há, para Artifoni, divergências: enquanto a primeira teria prezado por uma arte retórica elitista (a ars dictaminis), vaidosa, de ostentação, praticada nas universidades, e não teria se preocupado com os conteúdos, mas

${ }_{28}$ Os principais textos de Artifoni sobre Boncompagno são os dos anos de 1997 e 2002. Neles é que o autor formula a ideia das gerações. 
unicamente com os protocolos da retórica, a segunda teria popularizado tal arte, valorizando a retórica praticada pelos homens do povo e voltada o grande público, interessada em comover as massas (a ars concionandi); teria, enfim, tirado ela da reclusão universitária e lhe dado um uso prático no interior dos governos citadinos, que recrutaram os retóricos para a administração pública. Com isso teria se forjado, tendo a retórica como instrumento, uma verdadeira "paideia" comunal, caracterizada pelo fervor cívico, pela moralidade política e pela valorização da ética - inspiradas pelas antigas autoridades romanas, especialmente Cícero e Sêneca - e pelo entendimento de que as ações políticas, inclusive a fala, são circunstanciais e não podem obedecer a protocolos demasiado rígidos (ARTIFONI, 2000; 20II). Sobre a terceira geração, infelizmente, os trabalhos do autor aos quais tivemos acesso não tratam.

A proposta de Artifoni permite entender que um profissional como Albertano de Brescia tenha sido recrutado pelos governos citadinos para potencializar a capacidade persuasiva da palavra e, com ela, instar os cidadãos a perseguir o bem comum e a zelar pela paz, bem como para munir os funcionários públicos das técnicas necessárias à comunicação política e aos processos decisórios e judiciários. Homens como Albertano e Remígio constituíram uma verdadeira intelligentsia a serviço dos regimes comunais - ao contrário da geração anterior de mestres da retórica, que permaneceram em seus centros de saber e olharam com desprezo os regimes populares - cujo motor era a incessante e instável articulação entre interesses e grupos sociais díspares. Serviram-nos em campos distintos: nos notariados, nas cúrias podestatais e nos estabelecimentos eclesiásticos.

Destarte, é compreensível que os retóricos da segunda geração tenham se envolvido com problemas distintos e, logo, formulado respostas distintas das preocupações enfrentadas pelos profissionais da geração anterior. Nos tempos de Boncompagno de Signa as cidades italianas ainda lutavam pela emancipação face ao Império e a luta ainda parecia aberta, dados os sucessos militares de Frederico I, o Barbarruiva, que havia conseguido derrotar a Liga Lombarda e destruir sua principal componente, Milão. Frederico II imprimiu à Liga algumas derrotas, mas não conseguiu reverter os avanços obtidos pelos italianos na conquista de direitos políticos e econômicos (GILLI, 20II, p. 27-38). A partir da metade do século XIII, obtida a autonomia, a libertas que os propagandistas da primeira geração tanto enalteceram, defendidas as repúblicas citadinas, restava consolidar os governos locais e impedir que ruíssem frente ao facciosismo (suscitado, em grande medida, por partidários de imperadores e papas que disputavam os governos em cada cidade). Por isso os magistrados comunais e os clérigos - empenhados na cura animarum - recrutaram intelectuais como Albertano e Remígio, para que dessem vazão a uma pedagogia cívica que 
educasse os cidadãos para o exercício das liberdades republicanas recentemente conquistadas.

Essa nova estratégia de edificação da comunidade política não parece ter se restringido à geração do notário e do frade; ela encontra ecos na geração posterior, ativa no início do século XIV. Podem-se aventar alguns exemplos, brevemente. Bártolo de Sassoferrato (I313-I357), jurista perusino que Skinner aborda com certa atenção, se concentra no problema da tirania, ou seja, do governo que é mau e, portanto, ilegítimo, passível de deposição. Comumente se toma Bártolo enquanto um dos primeiros ideólogos da república como melhor forma de governo, mas pesquisas recentes têm apontado que o jurista chega mesmo a conceber a possibilidade de que não apenas monarquias, mas também repúblicas sejam tiranas ${ }^{29}$. Em autores como esse, tudo depende do grau de representatividade do governo, isto é, do quanto ele atende a diferentes cidadãos, grupos e partidos. Se uma república, mesmo que governada por uma coletividade, atendesse a poucos ou a uns em detrimento de outros, então ela seria uma oligarquia e as oligarquias podem ser tiranas.

Similarmente, uma monarquia podia ser o melhor governo se fosse justa, zelasse pelo bem comum e preservasse a paz, o que se conseguia através de um conselho que reunisse os homens mais sábios da comunidade para assessorar o governante a tomar as decisões mais prudentes possíveis, a julgar com compaixão e a socorrer os desvalidos; essa é a formulação que encontramos em Paulino de Veneza (I270-I344) ${ }^{30}$, frade franciscano que escreveu, em I3I4, o tratado De regimine rectoris ${ }^{31}$, dedicado ao nobre Marino Badoer, seu compatriota, que havia sido encarregado pela sua cidade de governar a ilha de Creta ${ }^{32}$.

A partir de Paulino e dos demais autores abordados, a conclusão é a de que esses homens não faziam, necessariamente, uma oposição entre república e monarquia (como a que se identificava no Império e no Papado). Quando os retóricos da primeira geração enalteceram a ideia de res publica, o que estava presente era uma noção de comunidade própria, não de regime de governo. Nesse sentido, crê-se, é que se pode compreender o

29 Na esteira de Skinner, Newton Bignotto (I998; 20I2) corrobora a visão de um Bártolo republicano. Mais recentemente, Letícia Dias Schirm (20II, 20I2a, 20I2b) tem procurado demonstrar a polissemia e as nuanças das ideias do jurista.

30 Para análises da obra de Paulino e de sua biografia, ver EVANGELISTI, 2002 e FINZI, I997.

3I Paulino praticamente copiou o tratado De regimine principum de Egídio Romano (I243-I3I6), também aluno de Tomás de Aquino; Egídio, por sua vez, escrevera a sua obra sobre as bases de um tratado similar, de autoria de seu mestre. Paulino e Egídio, portanto, disseminaram a análise tomista onde se tentava acompanhar a reflexão aristotélica sobre as formas de governo. Cabe frisar que os três autores aceitam com certa naturalidade a monarquia, embora só lhe concedam uma qualidade positiva quando ela observa o caráter público do governo, segundo a lógica que delineamos acima.

32 O regime que se experimentava em Veneza era bastante diferente daquele praticado nas comunas da Lombardia, Toscana e Úmbria, mas não entraremos nesse mérito aqui. Para tanto, ver o artigo de Claudio Finzi, acima reportado. 
ideal de liberdade que aqueles homens formularam: uma noção estreitamente vinculada à criação de uma nova comunidade política, fosse ela a ecclesia (Igreja) ou a civitas (cidade), em alguma medida separada do corpo do Império ${ }^{33}$.

Talvez essa ausência não fosse apenas questão de escolha, como sugere Skinner (2002, p. 44); talvez os retóricos italianos não entendessem a república como uma forma de governo, e sim como um "Estado", a própria comunidade política ou como o caráter público que devia ser conferido a ela e observado por qualquer governante, como se viu a partir de Emilio Panella. Afinal, assim como Cícero, Aristóteles também parece ter resistido em apontar uma melhor forma, priorizando também a defesa do bem comum como critério de validação do governo. Ou seja, mesmo em autores que se debruçaram sobre o problema das formas políticas, o que as determinava e qualificava para a defesa da liberdade ainda era o seu teor moral, a qualidade dos cidadãos que compunham a comunidade e exerciam o governo. Não se tratava de defender a república como valor, mas de buscar o bom governo, a despeito de sua forma.

\section{Conclusões}

Através do percurso aqui traçado vê-se, em primeiro lugar, que os ideias de liberdade e de república não foram unívocos ao longo do período estudado: considerando as três gerações propostas por Artifoni, eles mudam ao longo delas. Seus significados são intimamente vinculados aos contextos em que são enunciados: à medida que os retóricos identificam e enfrentam problemas diferentes e se inserem em lugares sociais diferentes, os sentidos que dão a essas ideias mudam.

No início do século XIII, com as cidades italianas ainda lutando pela sua autonomia em relação ao Império, liberdade e república aparecem como opostas a um governo estrangeiro e a uma comunidade apropriada por estrangeiros, privatizada, por assim dizer. Por isso os ideólogos das independências locais preenchem esse vocabulário com os sentidos do autogoverno e da comunidade que é plenamente pública. Já a partir da metade do século a liberdade ganha a conotação de virtude moral de cada cidadão, capaz de

33 Não cabe aqui esmiuçar as razões pelas quais os italianos deram início a inúmeros processos de separação do Império, mas cumpre dizer que eles se iniciaram como resposta a outra dinâmica: a de germanização do trono imperial (e também do trono petrino), a partir do deslocamento da coroa para o reino franco, com Carlos Magno (742-8I4) - e sua dominação sobre o reino Lombardo (em 774) - e, sobretudo, da fragmentação do mundo carolíngio e de um novo deslocamento da coroa imperial, desta vez para as casas nobiliárquicas da Bavária e da Saxônia, de onde provinha a família Staufen, representada por Frederico I e Frederico II. Para uma análise sobre os impactos do processo de germanização do trono papal na formação do ideal de libertas ecclesiae, cf. RUST, 20I0. Para uma apreciação da germanização do trono imperial e de suas consequências sobre os governos italianos, ver ABULAFIA, I988. 
garantir a liberdade coletiva, de toda a comunidade, na medida em que motiva o homem sobre o bem comum, une-o ao seu grupo social e o engaja na sua defesa. Dada a subjetivação do conceito de liberdade, a questão do melhor regime, do melhor tipo de governo, não preocupa os retóricos envolvidos com os governos citadinos: eles preferem investir na educação cívica para assegurar que o público ao qual se dirigem se empenhe moralmente com a virtude, o amor e a justiça e, por conseguinte, zele pela liberdade coletiva. Será, provavelmente, só no decorrer do século XIV que a república aparecerá como um regime oposto ao monárquico, representado pelos papas e imperadores.

\section{Referências}

Todas as traduções são de nossa autoria. Para as traduções da obra de Quentin Skinner, nos amparamos na tradução de Renato Janine Ribeiro e Laura Teixeira Motta, em edição de 2002. Para as dos textos remigianos, contamos com a ajuda da tradução de Emilio Panella para o italiano.

Como usamos muitas edições eletrônicas de fontes e bibliografia, muitas citações não puderam constar de páginas exatas, pois o suporte online não possui paginação.

\section{Fontes}

ALBERTANO DE BRESCIA. Liber consolationis et consolii. In: Albertani Brixiensis Liber consolationis et consilii, ex quo hausta est fabula gallica de Melibeo et Prudentia, quam, anglice redditam et The Tale of Melibe inscriptam, Galfridus Chaucer inter Canterbury tales recepit. Editado por Thor Sundby. Londres: [s.n.], I884. Disponível em: <https://archive.org/details/albertanibrixienooalbe>. Acesso em: I4 set 2015. [Disponível também na Latin Library: <http://www.thelatinlibrary.com/albertanus/albertanus.liberconsol.shtml >. Acesso em: I4 set 2015].

Ars loquendi et tacendi. In: In: Albertani Brixiensis Liber consolationis et consilii, ex quo hausta est fabula gallica de Melibeo et Prudentia, quam, anglice redditam et The Tale of Melibe inscriptam, Galfridus Chaucer inter Canterbury tales recepit. Editado por Thor $\begin{array}{lllll}\text { Sundby. } & \text { Londres: } & \text { [s.n.], } & \text { I873. } & \text { Disponível }\end{array}$ $<$ https://archive.org/details/albertanibrixienooalbe $>$. Acesso em: I4 set 20I5. [Disponível também 


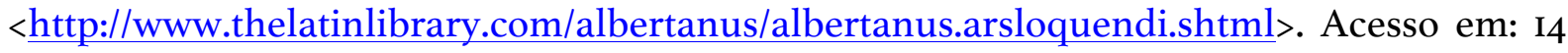
set 2015].

. De amore et dilectione Dei. Editado por Sharon Hiltz Romino e disponibilizado por Angus Graham. I980. Disponível em: <http://freespace.virgin.net/angus.graham/Albertano.htm $>$. Acesso em: I4 set 2015 . [Disponível também na Latin Library: <http://www.thelatinlibrary.com/albertanus.html>. Acesso em: I4 set 20I5].

. Sermo ianuensis. In: Sermone inedito di Albertano giudice di Brescia. Editado por Luigi Francesco Fè d'Ostiani em 1984. Brescia: Favoni, 1994. Disponível na Latin Library em: <http://www.thelatinlibrary.com/albertanus/albertanus.sermo.shtml>. Acesso em: I4 set 2015.

Sermo I. Editado por Gregory W. Ahlquist. 1997a. In: Latin Library. Disponível em: <http://www.thelatinlibrary.com/albertanus/albertanus.sermoI.shtml >. Acesso em: I4 set 2015.

. Sermo II. Editado por Gregory W. Ahlquist. 1997b. In: Latin Library. Disponível em: <http://www.thelatinlibrary.com/albertanus/albertanus.sermo2.shtml>. Acesso em: I4 set 2015.

. Sermo III. Editado por Gregory W. Ahlquist. 1997c. In: Latin Library. Disponível em: <http://www.thelatinlibrary.com/albertanus/albertanus.sermo3.shtml>. Acesso em: I4 set 2015.

. Sermo IV. Editado por Gregory W. Ahlquist. 1997d. In: Latin Library. Disponível em: <http://www.thelatinlibrary.com/albertanus/albertanus.sermo4.shtml $>$. Acesso em: I4 set 2015.

REMÍGIO DEI GIROLAMI. De bono communi. Editado por Emilio Panella. I985a. Disponível em: <http://www.smn.it/emiliopanella/remigioz/8500.htm>. Acesso em: I4 set 2015.

_. De bono pacis. Editado por Emilio Panella. 1985b. Disponível em: <http://www.smn.it/emiliopanella/remigio2/8500.htm>. Acesso em: I4 set 2015.

- Sermones de pace. Editado por Emilio Panella. 1985c. Disponível em: <http://www.smn.it/emiliopanella/remigio2/8500.htm>. Acesso em: I4 set 2015.

\section{Bibliografia}

ABULAFIA, David. Frederick II: a medieval emperor. Nova Iorque/Oxford: Oxford University Press, 1988. 
ARTIFONI, Enrico. Corporazioni e società di "popolo": un problema della politica comunale nel secolo XIII. Quaderni storici. Nuova serie. 74. Ano XXV. n. 2. [S.l.: s.n.], ago I990.

em:

$<$ https://www.academia.edu/384742/Corporazioni_e_societ\%C3\%Ao_di_popolo_un_proble ma_della_politica_comunale_nel_secolo_XIII>. Acesso em: 8 set 2015.

Sapientia Salomonis: une forme de présentation du savoir rhétorique chez les dictatores italiens (prèmiere moitié du XIIIe siècle). In: DESSİ, Rosa Maria \& LAUWERS, Michel (orgs.). La parole du prédicateur (Ve-XVe siècle). Collection du Centre d'Études Médiévales de Nice. v. I. Nice: [s.n.], I997. Disponível em: $<$ https://www.academia.edu/384745/Sapientia_Salomonis._Une_forme_de_pr\%C3\%A9senta tion_du_savoir_rh\%C3\%A9torique_chez_les_dictatores_italiens_premi\%C3\%A8re_moiti\%C 3\%A9_du_XIIIe_si\%C3\%A8cle_>. Acesso em: 8 set 2015 .

. L'éloquence politique dans les cités communales (XIIIe siècle). In: HEULLANTDONAT, Isabelle (org.). Cultures italiennes (XIIe-XVe siècle). Paris: Les Éditions du CERF, 2000. Disponível em: <https://www.academia.edu/5225503/L_\%C3\%Agloquence_politique_dans_le_cit\%C3\%A9s_ communales_XIIIe_si\%C3\%A8cle_>. Acesso em: 8 set 2015.

Boncompagno da Signa, i maestri di rettorica e le città comunali nella prima metà del Duecento. In: BALDINI, M. Il pensiero e l'opera di Boncompagno da Signa. Signa: [s.l.], 2002. Disponível em: <http://rm.univr.it/biblioteca/scaffale/Bibliografie/BiblioArtifoni.htm>. Acesso em: 24 ago 2015.

. I governi di "popolo" e le istituzioni comunali nella seconda metà del secolo XIII. Reti Medievali Rivista. IV. Florença: Firenze University Press, 2003. Disponível em: <http://rm.univr.it/rivista/dwnl/Artifoni.pdf $>$. Acesso em: 9 set 2015.

Prudenza del consigliare: l'educazione del cittadino nel Liber consolationis et consilii di Albertano da Brescia (I246). In: CASAGRANDE, Carla; CRISCIANI, Chiara; VECCHIO, Silvana (orgs.). Consilium: teorie e pratiche del consigliare nella cultura medievale. Florença: SISMEL / Edizioni del Gallluzzo, 2004. Disponível em: $<$ https://www.academia.edu/2048384/Prudenza_del_consigliare._L_educazione_del_cittadin o_nel_Liber_consolationis_et_consilii_di_Albertano_da_Brescia_I246_>. Acesso em: 8 set 2015 .

. Comune italiano. In: Federico II. Enciclopedia Fridericiana. v. I. Roma: Istituto della Enciclopedia Italiana, 2005. Disponível em: <http://www.treccani.it/enciclopedia/comuneitaliano_(Federiciana)/>. Acesso em: 8 set 2015. 
. Segreti e amicizie nell'educazione civile dell'età dei comuni. In: Micrologus: natura, scienze e società medievali. Il segreto. XIV. Florença: SISMEL / Edizioni del Galluzzo, 2006. Disponível em: $<$ https://www.academia.edu/2048389/Segreti_e_amicizie_nell_educazione_civile_dell_et\%C 3\%Ao_dei_comuni $>$. Acesso em: 8 set 2015.

. Notes sur les équipes des podestats et sur la circulation de modèles culturels dans l'Italie du XIIIe siècle. In: SOCIETÉ DES HISTORIENS MÉDIÉVISTES DE L'ENSEIGNEMENT SUPÉRIEUR PUBLIC. Des sociétés en mouvement: migrations et mobilité au Moyen Âge. XLe Congrès de la SHMESP (Nice, 4-7 juin 2009). Histoire Ancienne et Médiévale - I04. Paris: Sorbonne, 20I0. Disponível em: $<$ https://www.academia.edu/2050742/Notes_sur_les_\%C3\%A9quipes_des_podestats_et_sur_1 a_circulation_de_mod\%C3\%A8les_culturels_dans_I_Italie_du_XIIIe_si\%C3\%A8cle>. Acesso em: 8 set 2015 .

. Il silenzio efficace nella rettorica laica del Duecento italiano. In: Micrologus: natura, scienze e società medievali. Il silenzio. XVIII. Florença: Edizioni del Galluzzo, 20 Io. Disponível em: <https://www.academia.edu/2048394/Il_silenzio_efficace_nella_retorica_laica_del_Duecent o_italiano>. Acesso em: 9 set 2015.

. L'oratoria politica comunale e i "laici rudes et modice literati". In: DARTMANN, Christoph; SCHARFF, Thomas; WEBER, Christoph Friedrich (orgs.). Zwischen pragmatik und performanz: dimensionen mittelalterlicher schriftkultur. Turnhout: Brepols, 201 I. Disponível em: $<$ https://www.academia.edu/2048395/L_oratoria_politica_comunale_e_i_laici_rudes_et_mod ice_literati_>. Acesso em: 8 set 2015.

BIGNOTTO, Newton. O silêncio do tirano. Revista USP. 37. São Paulo: março/maio I998. Disponível em: $<$ http://www.usp.br/revistausp/37/I3-newton.pdf $>$. Acesso em: I4 set 2015.

O Humanismo e a linguagem política do Renascimento: o uso das Pratiche como fonte para o estudo da formação do pensamento político moderno. Caderno CRH. v. 25. n. spe 02. Salvador, 2012.

CAPITANI, Ovidio. Girolami, Remigio dei. In: Enciclopedia Dantesca. 1970. Disponível em: $<$ http://www.treccani.it/enciclopedia/remigio-dei-girolami_(Enciclopedia-Dantesca)/>. Acesso em: 13 set 2015.

EVANGELISTI, Paolo. I pauperes Christi e i linguaggi dominativi: i francescani come protagonisti della costruzione della testualità politica e dell'organizzazione del consenso nel bassomedioevo (Gilbert de Tournai, Paolino da Venezia, Francesc Eiximenis). In: La 
propaganda politica nel Basso Medioevo. Atti del XXXVIII Convegno storico Internazionale. Todi, I4-I7 ottobre 200I. Espoleto: 2002.

FINZI, Claudio. La formazione dello stato patrizio: la vita civile e religiosa. Scritti storicopolitici. In: Storia di Venezia. Cap. III. [S.l.: s.n.], I997. Disponível em: $<$ http://www.treccani.it/enciclopedia/la-formazione-dello-stato-patrizio-la-vita-civile-ereligiosa-scritti-storico-politici_\%28Storia-di-Venezia\%29/>. Acesso em: 6 jul 2013.

GENTILI, Sonia. Girolami, Remigio de'. In: Dizionario Biografico degli Italiani. v. 56. 20oI. Disponível em: <http://www.treccani.it/enciclopedia/remigio-degirolami_\%28Dizionario-Biografico\%29/>. Acesso em: 13 set 2015.

GILLI, Patrick. Cidades e sociedades urbanas na Itália medieval (séculos XII-XIV). Campinas: UNICAMP / Belo Horizonte: UFMG, 20II.

GUERRINI, Paolo. Albertano da Brescia. In: Dizionario Biografico degli Italiani. v. I. Disponível na Enciclopedia Treccani, em: <http://www.treccani.it/enciclopedia/albertanoda-brescia_\%28Dizionario-Biografico\%29/>. Acesso em: I jun 2015. [S.l.: s.n.], I960.

MEIER, Christian. Política e graça. Brasília: UnB, 1997.

MONTEVERDI, Angelo. Albertano da Brescia. In: Enciclopedia Italiana. 1929. Disponível na Enciclopedia Treccani, em: <http://www.treccani.it/enciclopedia/albertano-dabrescia_(Enciclopedia-Italiana)/>. Acesso em: I4 set 2015.

RUST, Leandro Duarte. "Colunas vivas de São Pedro": concílios, temporalidades e reforma na história institucional do papado medieval (IO46-I2I5). Tese apresentada ao Programa de Pós-Graduação em História da Universidade Federal Fluminense como requisito parcial para a obtenção do grau de Doutor. Área de concentração: História Social. Setor temático de História Medieval. Niterói: 20ı. Disponível em: <http://www.historia.uff.br/stricto/td/I208.pdf >. Acesso em: II nov 2015.

SCHIRM, Letícia Dias. Estudo da tirania medieval como uma cultura política: possibilidades? Atas XVIII Encontro Regional da ANPUH/MG. 24 a 27 de julho de 20I2a. Mariana, MG. Disponível em: <http://www.encontro20I2.mg.anpuh.org/resources/anais/24/I340765432_ARQUIVO_Tirani aComoCulturaPolitica-possibilidades-LeticiaDiasSchirm.pdf $>$. Acesso em: I4 set 2015.

. Regimine civitatis: apontamentos sobre o regimen no tardo-medievo. Atas do Primeiro Encontro de Pesquisa em História da UFMG. 23 a 25 de maio de 20I2b. Disponível em: $<$ https://pt.scribd.com/doc/I5844I329/Anais-Eletronicos-EPHIS-Vol-2>. Acesso em: I set 2015.

Omnem e iurisdictio: comentários de Bartolus da Sassoferrato (I3I4-I357) sobre Dominium. Dissertação (Mestrado em História), Universidade Federal de Minas Gerais, 
Faculdade de Filosofia e Ciências Humanas. Belo Horizonte, 20II. Disponível em: <http://www.bibliotecadigital.ufmg.br/dspace/bitstream/handle/I843/BUOS-

8LXJEV/omnemeiurisdictio_coment_riosdebartolusdasassoferrato__I3I4_I357_sobredomin ium.pdf?sequence=I>. Acesso em: I4 set 2015.

SKINNER, Quentin. The origins of the Renaissance. In: The foundations of modern political thought. Volume one: the Renaissance. Cambridge: Cambridge University Press, 2002 [Primeira edição: 1978]. As origens da Renascença. In: As fundações do pensamento político moderno. Tradução de Renato Janine Ribeiro e Laura Teixeira Motta. São Paulo: Companhia das Letras, 1996. . Machiavelli's Discorsi and the pre-humanist origins of republican ideas. In: BOCK, Gisela; SKINNER, Quentin; VIROLI, Maurizio (orgs.). Machiavelli and Republicanism. Cambridge: Cambridge University Press, 1990.

STOCCHI, Manlio Pastore. Albertano da Brescia. In: Enciclopedia Dantesca. 1970. Disponível na Enciclopedia Treccani, em: <http://www.treccani.it/enciclopedia/albertano-dabrescia_(Enciclopedia-Dantesca)/>. Acesso em: I4 set 2015.

ZORZI, Andrea. La cultura della vendetta nel conflitto politico in età comunale. In: ZORZI, Andrea \& DONNE, Roberto delle (orgs.). Le Storie e la memoria: in onore di Arnold Esch. Florença: Firenze University Press, 2002.

- "Fracta est civitas magna in tres partes": Conflitto e costituzione nell'Italia comunale. Scienza \& Politica. 39. 2008. Disponível em: $<$ http://scienzaepolitica.unibo.it/article/viewFile/2749/2I46>. Acesso em I4 sete 2015. (org.). Conflitti, paci e vendette nell'Italia comunale. Florença: Firenze University Press, 2009. Disponível em: <http://www.fupress.com/archivio/pdf/4265.pdf $>$. Acesso em: I4 set 2015. 